\title{
Solvency Evaluation Model of Insurance Company Based on Stochastic Differential Equation
}

\author{
Kai Wang $(\mathbb{D}$ and Ling Zhu $(\mathbb{D}$ \\ School of Science, Anhui Agricultural University, Hefei 230036, China \\ Correspondence should be addressed to Kai Wang; kaywang@163.com \\ Received 2 March 2021; Revised 22 March 2021; Accepted 29 March 2021; Published 16 April 2021 \\ Academic Editor: M. Irfan Uddin \\ Copyright ( $\odot 2021$ Kai Wang and Ling Zhu. This is an open access article distributed under the Creative Commons Attribution \\ License, which permits unrestricted use, distribution, and reproduction in any medium, provided the original work is \\ properly cited.

\begin{abstract}
Solvency assessment is the core content of insurance supervision. In this paper, from the perspective of capital flow, the insurance company's capital flow is regarded as a dynamic system, the stochastic differential equations model is established to describe its flow characteristics, and the existence of positive equilibrium point of the system is proved, as well as the conditions of stability at equilibrium point, that is, the requirements of the insurance company's solvency. Furthermore, by using the numerical simulation method, we get the strategy of insurance companies to deal with the solvency shortage when facing the change of external environment, and the strategy of insurance company to deal with solvency shortage is obtained.
\end{abstract}

\section{Introduction}

From the perspective of capital flow, this paper uses stochastic differential equations to establish a model to determine the conditions for an insurance company to obtain dynamic solvency, analyzes and numerically simulates these conditions, and puts forward the strategies for an insurance company to maintain solvency when the external environment changes.

Solvency regulation is the core of insurance regulation [1], such as the RBC system implemented in the United States, the Solvency system launched by the European Union, and C-ROSS system implemented in China. Even after many reforms, no matter which stage, the insurance companies are supervised around solvency. Therefore, a reasonable assessment of the solvency of insurance companies is an important prerequisite for effective supervision.

In the current solvency supervision system, solvency assessment is mainly to identify and predict the risks faced by insurance companies, determine the risk capital required to deal with each risk, and use correlation or the coupla method to comprehensively calculate the overall risk capital requirements and then compare it with the actual capital of insurance companies. If the actual capital exceeds the risk capital requirements, the insurance company is considered to have solvency; otherwise, it does not have solvency.

This evaluation method ignores the dynamic nature of solvency, which is shown in many cases in reality; for example, the AIG insurance group in the United States, $\mathrm{HIH}$ insurance company in Australia, and general motor insurance company in the United Kingdom all met the requirements of solvency supervision and met the capital requirements in the annual actuarial report. However, in a short period of six months, due to various reasons such as asset shrinkage and insufficient solvency, the company was taken over or even went bankrupt.

This paper mainly from the perspective of insurance company's capital flow divides its capital into different states, regards the insurance company as the flow system of capital between warehouses in different states, uses stochastic differential equations to describe the system, and determines the condition for insurance companies to maintain sufficient capital in each state, that is, the condition of solvency. Also, through the analysis of the conditions and numerical simulation, the strategy of insurance company's continued solvency is obtained. This paper not only widens the 
application field of stochastic differential equation but also puts forward a new solvency evaluation method, which can be used as an important supplement to solvency supervision.

\section{Related Work}

The article on solvency evaluation and supervision mainly includes three aspects: the analysis of the existing solvency supervision system, the analysis of the optimal strategies of insurance companies in investment, pricing, and management under the framework of the current supervision system, and the evaluation of solvency by different methods. In addition, there are a few applications of stochastic differential equations in the analysis of investment strategies of insurance companies.

2.1. Analysis of Solvency Supervision System. The representatives of the current solvency supervision system are RBC system of the United States, Solvency II of the European Union, and C-ROSS of China. There are many analyses about Solvency II, and different scholars point out the shortcomings of Solvency II from different angles. Drenovak et al. [2] considered that Solvency II regulatory system leads to the lack of diversification of bond portfolio and higher credit risk of insurance companies. Pelkiewicz et al. [3] think Solvency II ignores the risk margin and is too sensitive to the change in interest rate, especially for annuity business. Moreover, the reduction in risk margin leads to the increase in reinsurance business risk of insurance companies, especially overseas reinsurance companies. Cooke et al. [4] also found that Solvency II reduces the impact of risk margin and reduces the technical reserve of insurance companies. Rae et al. [5] believed that Solvency II has not achieved the expected goal, and there are still some areas that need to be adjusted and improved in terms of procyclicality and market consistency. Pablo Duran etal. [6] using the nonsmoothing technique found that Solvency II has a lower minimum capital requirement than the solvency assessed by the standard model. Scherer and Stahl [7] think that Solvency II's standard formula is better than I in risk sensitivity and so on, but the stochastic model still has great uncertainty. Gunther and Richter [8] found that the current standard formula of solvency capital requirement cannot correctly reflect the catastrophe risk of life for the trend of more liquidity of risk. Tan and Bruhn [9] compared Solvency II centered in Europe with life and general insurance capital systems centered in Australia. The results show that different regulatory systems have different requirements for solvency.

\subsection{Analysis on the Behavior Strategy of Insurance Companies} under the Supervision System. Solvency supervision system will also have an impact on the behavior of insurance companies. Di Francesco [10] proposed a multiobjective portfolio optimization model for non-life insurance companies based on Solvency II's capital requirements, market view, and confidence level, using the entropy pool method. Fernandez-Arjona [11] used the neural network to build a model and solved the problem of feature engineering and feature selection in portfolio. Braun et al. [12] according to the capital cost under the solvency model determine the effective portfolio composition that can be used for a given amount of external equity. The results show that the standard formula has serious shortcomings and interferes with rational asset management decisions. Escobar et al. [13] believe that Solvency II's capital requirements lead to restrictions on investment strategies. The closed-form approximation of the optimal investment strategy is obtained by using the two-step method under the constraint of capital requirement. A numerical example is used to evaluate the impact of these constraints on asset allocation and the performance of these strategies. Asimit et al. [14] in the framework of Solvency II proposed a two-level optimization model with ruin probability as the insurance solvency constraint, which simultaneously solves the problems of optimal required capital and portfolio structure.

The aspects such as pricing, management, and finance are also studied under the existing regulatory system. Nicolino et al. [15] according to the Solvency II regulations found that the pricing of reinsurance is determined under different levels of capital cost rate, and a lower cost level is provided. Pfeifer [16], based on the quantile diagram, proposed the analysis method of deviation from Solvency II standard formula for reserve, premium risk, and their combination ratio. Durán Santomil and Otero González [17] put forward an index to measure the quality of ERM implementation of insurance companies from the perspective of originality and value cost by investigating CRO of Spanish insurance companies. Jansen van Vuuren et al. [18] investigated the impact of the second pillar of solvency assessment and management (SAM) on risk management of South African insurance companies. It is found that there is a gap between risk management practice and management requirements. Wang et al. [19] found that, under the current accounting standards, the regulatory system led to some property insurance companies operating financial statements.

2.3. Solvency Estimate. Based on the identification of risks, different scholars put forward different methods of solvency assessment of insurance companies. Lu and Hong [20] used the Monte Carlo simulation method, combined with the historical loss and current financial data, and established a self-insurance fund solvency prediction model. MuchaMichal and Páleś-Katarína [21] also used the Monte Carlo simulation method to generate the value of total claim amount for statistical processing, so as to meet the needs of the capital required by solvency. Bermúdez et al. [22] using the Monte Carlo method to simulate the data of Spanish non-life insurance market from 2000 to 2009 found that the correlation assumption between different insurance business lines will have a significant impact on risk capital. Mejdoub and Ben Arab [23] used copula function modeling to estimate venture capital based on the data of an insurance company in Tunisia and verified its availability with the Monte Carlo method. Hanewald et al. [24] based on the research of macroeconomic fluctuation and demography 
developed a dynamic asset liability model to evaluate the impact of macroeconomic fluctuation on the solvency of life insurance companies. Valecký [25] uses the GLM model to calculate solvency capital requirement of non-life insurance underwriting risk by using individual rating factors. Vaucher [26] proposed an optimal choice of put option contract to reduce the capital cost related to equity investment. It is considered that the risk-based capital requirements provide greater incentives for the use of derivatives in the context of risk mitigation.

\subsection{Application of Stochastic Differential Equation in} Insurance. The application of stochastic differential equations in insurance is still relatively few. Delong [27] considered financial risk, systematic and unsystematic insurance loss risk (including longevity risk), and the possible dependence between them. By using the backward stochastic differential equation (BSDE) technique and the weak property of predictable representation, the optimal asset allocation is obtained. Delong and Gerrard [28] used the stochastic differential equation driven by Brownian motion to describe the change process in claim intensity and applied the stochastic control theory to find the optimal game when the wealth of the insurance company deviates from the specified profit solvency target. Xiong [29] studied the diffusion model and its application in risk theory and insurance and proved that the expected discounted penalty function is an extension of ruin probability, which satisfies an elliptic partial differential equation under certain initial boundary conditions. Shi et al. [30] combining risk tolerance and utility attitude with decision-making objectives choose BSDE to establish the model and obtain the actual pricing formula of unit-linked life insurance products. Paul [31] takes the solvency capital requirement as the constraint condition and uses the deterministic control theory to find the optimal premium strategy. Floryszczak et al. [32] for financial institutions with long-term commitment use stochastic differential equation to establish a model to evaluate solvency capital requirements and budget allocation and proves the existence, uniqueness, and stability of the solution of the model.

\section{Model}

This paper attempts to avoid the traditional method of establishing minimum capital requirement to evaluate solvency through risk identification, classification, and measurement but, from the perspective of capital flow, establishes a dynamic solvency evaluation model, so as to achieve the purpose of dynamic prediction and expand the regulatory model, which takes the capital requirement as the only standard.

3.1. Capital Flow Analysis. Insurance organization is a system. The energy of the system comes from the fund. On the one hand, the fund brought by premium income provides the power for it. On the other hand, the fund flowing out of compensation expenditure provides insurance protection for the policyholder. At the same time, in the process of operation, it uses the capital advantage to realize the asset appreciation through investment.

Therefore, we can use the idea of compartment model to divide the fund of insurance organization into three states: health fund, risk fund, and reserve fund. The flow of fund is regarded as the transfer of fund between each state, as shown in Figure 1.

After entering the system, the insurance organization's capital source, premium income, is in a healthy state at first, and at the same time, part of it is spent in the form of underwriting expenses and so on and moves out of the system. Then, part of the health fund is transferred to the reserve state for future claim, and part of the health fund is transferred to the risk state for investment. When the capital is in the state of risk, it will realize increment or loss through investment, and part of it will be used for investment expenses and other expenses, which will be moved out of the system, and part of it may be transferred to reserves. When part of the funds in the state of health and risk enter the reserve state, they are mainly used to pay claim and move out of the system.

Obviously, for the system of insurance organization, as long as the capital inflow exceeds the capital outflow, and each state of the system keeps the capital greater than zero, then the system can operate and has solvency. Insurance organizations can control the transfer of funds within the system to keep the capital flow stable and avoid the occurrence of future capital flow rupture. Of course, the comparison of capital inflow and capital outflow is not a simple subtraction because the process of capital flow is not a deterministic transfer, but random interference, such as the increase or decrease in premium income, the fluctuation of investment yield, and the occurrence of unknown claim will bring unexpected changes in the state of capital flow.

Therefore, we can use the stochastic differential equation to describe the dynamic process of capital flow in an insurance organization system. According to the stability theory, we can analyze whether the fund in each state will be stable in a positive value or fluctuate around it in the future and what are the conditions to be stable in a positive value; hat is, under the current fund allocation scheme, whether the insurance organization can guarantee the stable holding of funds and solvency in each state in the future and what kind of control scheme should be adopted for the capital flow to maintain the solvency state in the future should be studied.

3.2. Model. According to the analysis of the capital flow of insurance organization, the stochastic differential equation is used to describe the dynamic process, and the model is established:

(1) For the healthy state, the capital in the healthy state at the time of $t$ is $S(t)$, and its change includes two parts: the capital inflow part and the capital outflow part.

Assuming that the growth rate of premium is $\lambda$ and the premium ceiling is $K$, the dynamic change process is as follows: 


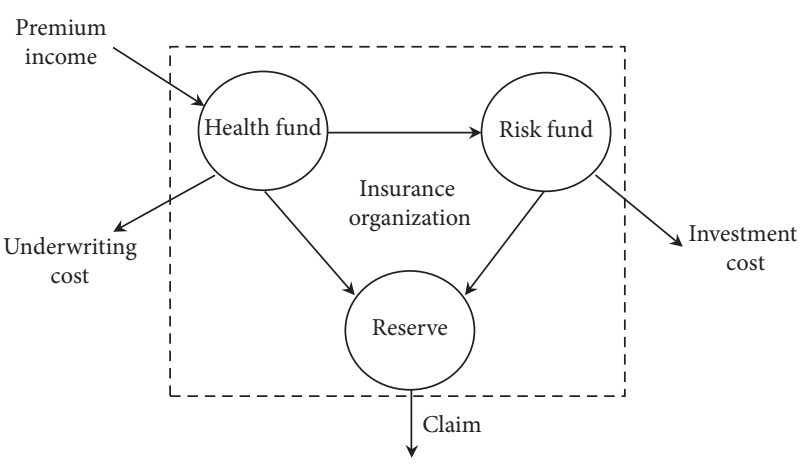

FIgURE 1: Capital flow system of insurance organization.

$$
\mathrm{d} S(t)=\left(S+\lambda S\left(1-\frac{S}{K}\right)\right) \mathrm{d} t
$$

The dynamic change process of healthy state fund is modified as follows: a part of healthy state fund outflow is used to pay underwriting expenses and transferred out of the system, the underwriting expense rate is $d_{1}$, a part of healthy state fund outflow is used to invest and transfer to risk state, the transfer ratio is $\beta$, a part of healthy state fund outflow is used to draw reserves and transferred to reserve state, and the transfer ratio is $\omega$ :

$$
\mathrm{d} S(t)=\left(S+\lambda S\left(1-\frac{S}{K}\right)-\beta S-\omega S-d_{1} S\right) \mathrm{d} t
$$

In reality, the capital flow such as premium income is subject to random interference. Assuming that the random interference obeys Brownian motion, the dynamic change process of healthy capital is modified as follows:

$\mathrm{d} S(t)=\left(S+\lambda S\left(1-\frac{S}{K}\right)-\beta S-\omega S-d_{1} S\right) \mathrm{d} t+\sigma_{1} S \mathrm{~d} B_{1}(t)$

where $\sigma_{1}$ is the standard deviation of capital flow fluctuation in healthy state.

(2) For the risk state, the capital in the risk state at time $t$ is $I_{t}$, and its change is also divided into two parts: the capital inflow part and the capital outflow part.

The dynamic change process of the capital inflow is as follows: the capital inflow is in the healthy state and transferred to the risk state:

$$
\mathrm{d} I(t)=\beta S \mathrm{~d} t .
$$

If the capital is used for investment in the risk state, it will realize its own value-added. If the rate of return on investment is $r$, its own value-added process is as follows:

$$
\mathrm{d} I(t)=r I \mathrm{~d} t
$$

The dynamic change process of capital outflow in the risk state is as follows: part of capital outflow in the risk state is used to pay investment expenses and transferred out of the system, and the investment expense rate is $d_{2}$; part of capital outflow in the health state is used to draw reserves and transferred to the reserve state, and the transfer ratio is $\mu$ :

$$
\mathrm{d} I(t)=\left(-\mu I-d_{2} I\right) \mathrm{d} t .
$$

In reality, the rate of return on investment is subject to random interference. Assuming that the random interference obeys Brownian motion, the dynamic change process of risk state capital is as follows:

$$
\mathrm{d} I(t)=\left(\beta S+r I-\mu I-d_{2} I\right) \mathrm{d} t+\sigma_{2} I B_{2}(t),
$$

where $\sigma_{2}$ is the standard deviation of capital flow fluctuation in risk state.

(3) For reserve status, the capital at the time of $t$ is $R(t)$, and its change is also divided into capital inflow and capital outflow.

The dynamic process of capital inflow is as follows: the capital flows from the healthy state and the risk state to the reserve state:

$$
\mathrm{d} R(t)=(\omega S+\mu I) \mathrm{d} t
$$

If the outflow of funds in reserve status is used for claim and other related expenses and transferred out of the system and the reserve payment rate is $d_{3}$, the dynamic change process of outflow of funds in reserve status is as follows:

$$
\mathrm{d} R(t)=-d_{3} R \mathrm{~d} t
$$

Similarly, in reality, the occurrence of claim events is random. Assuming that it obeys Brownian motion, the dynamic change process of reserve fund is as follows:

$$
\mathrm{d} R(t)=\left(\omega S+\mu I-d_{3} R\right) \mathrm{d} t+\sigma_{3} R \mathrm{~d} B_{3}(t),
$$

where $\sigma_{3}$ is the standard deviation of capital flow fluctuation in reserve status.

(4) For the capital flow system of insurance organization, the dynamic process of capital flow of the whole system can be described by combining the dynamic changes in health state, risk state, and reserve state. However, it is noted that the proportion of funds transferred from healthy and risk states to reserve state is related to the reserve payment rate $d_{3}$, which is the function of $\omega$ and $\mu$ with respect to $d_{3}$, and is recorded as $\omega\left(d_{3}\right)$ and $\mu\left(d_{3}\right)$, respectively. Generally speaking, the higher the claim is, the greater the reserve payment rate is, and the greater the proportion of funds transferred from the healthy state 
and risk state to the reserve state is. Therefore, the function can be simply assumed as $d_{3} \omega$ and $d_{3} \mu$. In fact, $d_{3} \omega$ and $d_{3} \mu$ are the actual loss ratio, that is, the proportion of the actual claim in the healthy state and the risk state, respectively. This is more in line with the reality because the outflow of funds in the health and risk states is the expenditure that needs to be paid, while the reserve is only an estimate of the future, and the book provision is not the actual expenditure.

Therefore, the transfer ratio in equations (3), (7), and (10) can be modified to $d_{3} \omega$ and $d_{3} \mu$, respectively, and the dynamic stochastic equation of insurance organization capital flow system can be obtained simultaneously:

$\left\{\begin{array}{l}\mathrm{d} S(t)=\left(S+\lambda S\left(1-\frac{S}{K}\right)-\beta S-d_{3} \omega S-d_{1} S\right) \mathrm{d} t+\sigma_{1} S \mathrm{~d} B_{1}(t), \\ \mathrm{d} I(t)=\left(\beta S+r I-d_{3} \mu I-d_{2} I\right) \mathrm{d} t+\sigma_{2} I B_{2}(t), \\ \mathrm{d} R(t)=\left(d_{3} \omega S+d_{3} \mu I-d_{3} R\right) \mathrm{d} t+\sigma_{3} R \mathrm{~d} B_{3}(t) .\end{array}\right.$

It is noted that the parameters $\lambda, r, d_{1}, d_{2}, d_{3}, \sigma_{1}, \sigma_{2}$, and $\sigma_{3}$ are mainly dependent on the changes in the external environment and cannot be controlled by the insurance organization independently, so only the parameters $\beta, \omega$, and $\mu$ are the control variables of the insurance organization; that is to say, the insurance organization can adjust the change in capital flow by controlling these parameters to make the system reach a stable state.

\section{Results and Analysis}

4.1. Results. According to the dynamic stochastic equation (11) of insurance organization capital flow system established above, Proposition 1 can be obtained.

Proposition 1. Let $(S(t), I(t), R(t))$ be the solution of any initial value $(S(0), I(0), R(0)) \in R_{+}^{3}$ of the system. If

(1) $\lambda+1-\left(\beta+d_{3} \omega+d_{1}\right)>0$

(2) $-r+d_{3} \mu+d_{2}>0$

(3) $-r+\left(d_{3} \mu / 2\right)+d_{2}-(\beta / 2)>0$

(4) $d_{3}-\left(d_{3} \omega / 2\right)-\left(d_{3} \mu / 2\right)>0$

(5) $\sigma_{2}^{2} \leq-2 r+d_{3} \mu+2 d_{2}-\beta$

(6) $\sigma_{3}^{2} \leq 2 d_{3}-d_{3} \omega-d_{3} \mu$

then

$\limsup _{t \rightarrow \infty} \frac{1}{t} \int_{0}^{t}\left(\left(S-S^{*}\right)^{2}+\left(I-a I^{*}\right)^{2}+\left(R-b R^{*}\right)^{2}\right) \mathrm{d} s \leq \frac{K_{\sigma}}{M}, \quad a . \mathrm{s}$,

where

$$
\begin{aligned}
S^{*} & =\frac{K}{\lambda}\left(1+\lambda-\left(\beta+d_{3} \omega+d_{1}\right)\right), \\
I^{*} & =\frac{\beta}{-r+d_{3} \mu+d_{2}} S^{*}, \\
R^{*} & =\omega S^{*}+\mu I^{*}, \\
M & =\min \left\{r+\frac{d_{3} \mu}{2}+d_{2}-\frac{\beta}{2}-\frac{1}{2} \sigma_{2}^{2}, d_{3}-\frac{d_{3} \omega}{2}-\frac{d_{3} \mu}{2}-\frac{1}{2} \sigma_{3}^{2}\right\}, \\
K_{\sigma} & =\frac{K}{2 \lambda}\left(\frac{d_{3} \omega}{2}+\frac{d_{3} \mu}{2}+1\right) S^{*} \sigma_{1}^{2}+a I^{* 2} \sigma_{2}^{2}+b R^{* 2} \sigma_{3}^{2}, \\
a & =\frac{r+\left(d_{3} \mu / 2\right)+d_{2}-(\beta / 2)}{r+\left(d_{3} \mu / 2\right)+d_{2}-(\beta / 2)-(1 / 2) \sigma_{2}^{2}}, \\
b & =\frac{d_{3}-\left(d_{3} \omega / 2\right)-\left(d_{3} \mu / 2\right)}{d_{3}-\left(d_{3} \omega / 2\right)-\left(d_{3} \mu / 2\right)-(1 / 2) \sigma_{3}^{2}} .
\end{aligned}
$$

The proof is in Appendix.

Proposition 1 shows that as long as the capital flow control of an insurance organization satisfies conditions (1)-(6), the fund in each state can be stable in a limited range near $\left(S^{*}, a I^{*}, b R^{*}\right)$ in the future.

4.2. Result Analysis. The following is a discussion on the capital flow control conditions (1)-(6).

Condition (1): $\lambda+1-\left(\beta+d_{3} \omega+d_{1}\right)>0$.

The parameter $\lambda$ is the growth rate of premium income, $\beta, d_{3} \omega$, and $d_{1}$ are the proportion of transferring to risk, reserve, and moving out of the system, respectively, then $1-$ $\left(\beta+d_{3} \omega+d_{1}\right)$ is the capital stock in healthy state, so condition (1) requires that the capital inflow and stock in healthy state are greater than the capital outflow ratio so that the insurance organization can ensure that the capital in healthy state will not be consumed completely.

Obviously, to meet this condition, the greater the $\lambda$, the better the results; that is, the faster the premium growth of the insurance organization, the more the capital inflow, and the more healthy the capital. If the premium income growth rate is too low, or even negative growth occurs, the system will be difficult to meet condition (1) and may tend to fail.

At the same time, the smaller the parameter $d_{1}$, the better the results, that is to say, the lower the underwriting expenses, and more funds can be kept in a healthy state.

The smaller the parameter $d_{3} \omega$ is, the better the results. Obviously, the less the claim, the more the insurance organizations accumulate funds. If the claim is too high and the growth of premium income cannot catch up with the claim, the system will not reach a stable state, and the insurance organizations cannot have the solvency.

Among them, parameter $\omega$, the reserve ratio of healthy funds, belongs to the decision variable. However, when the reserve payment ratio $d_{3}$ increases, although condition (1) can be satisfied by reducing $d$ from the mathematical 
expression, it is obvious that the reserve ratio is related to the reserve payment ratio. If the reserve payment ratio is reduced, it will actually increase the reserve payment ratio. Therefore, it is necessary to increase the reserve payment ratio $\omega$ to reduce the reserve payment ratio $d_{3}$. In order to meet condition (1), of course, due to the reverse change of the two and $d_{3}$ is determined by the external environment, the role of decision variable $\omega$ is limited, and it is more effective to control another decision variable $\beta$.

Parameter $\beta$ is also a decision variable, which is the part of health state funds transferred to risk state. It is the investment decision within the insurance organization and can be completely controlled by the internal system. Obviously, if the growth rate of premium income decreases, we need to reduce the funds transferred to the risk state, reduce the investment, and meet condition (1) under the condition of ensuring the expenses and claim so that the system can tend to a stable state. Similarly, if the actual loss ratio or expense ratio increases, it is also necessary to reduce the proportion of investment, reduce the risk, and meet condition (1) to ensure the stability of the system.

Obviously, the higher the premium growth rate $\lambda$, the smaller the actual loss ratio $d_{3} \omega$ and expense ratio $d_{1}$, the easier it is to meet condition (1), the larger the operation space of the insurance organization to the decision variable $\beta$, the stronger the control power, the easier it is to stabilize through the adjustment of capital flow allocation, the more stable the development of the insurance organization, and the more reliable it has the dynamic solvency.

For conditions (2) (3) (5), we can see that condition (5) is a subset of conditions (2) and (3) and only condition (5) needs to be satisfied. That is to meet,

$$
\sigma_{2}^{2} \leq-2\left(r-d_{2}\right)-\beta+d_{3} \mu
$$

Obviously, the smaller the volatility $\sigma_{2}$ of risk state capital flow, the easier the system is to be stable, but the investment risk is more determined by the external market environment. Although the insurance organization can reduce the risk through the investment portfolio, it cannot be completely determined by the insurance organization.

According to condition (5), the smaller the actual return on investment $r-d_{2}$ is, the more stable the system will be, because the higher the return on investment is, the higher the risk will be, the greater the fluctuation will be, and it is more difficult to reach a stable state.

At the same time, the smaller the parameter $\beta$ is, the more satisfied condition (5) is; that is to say, the smaller the proportion of funds entering the risk state is, the easier the system is to reach a stable state. Of course, it is obviously not in line with the actual operation of insurance organizations to blindly reduce the proportion of investment or the rate of return on investment in order to stabilize the system. From condition (5), we can see that when the rate of return on investment is high or the proportion of investment is large, it needs to be controlled by another decision variable $d_{3} \mu$, and condition (5) can be satisfied by increasing the parameters. $d_{3} \mu$ is the part of the fund that moves out of the risk state. Condition (5) requires that the difference between this part and the part that flows in the risk state should not be less than the fluctuation range. In fact, the fund that moves out of the risk state should be able to resist the risk faced by the fund that is in the risk state; that is to say, the insurance organization should make appropriate adjustment and control according to the investment status in order to ensure the system to enter a stable state. It can be seen that the more robust the investment is, the lower the risk $\sigma_{2}$ is. Although the rate of return $r-d_{2}$ is low, the system is easier to be stable, and there is more space to control the decision variable $\mu$, which is more convenient for insurance organizations to make the system stable through internal decision-making and operation and has stronger reliability of dynamic solvency.

For conditions (4) and (6), it can also be seen that condition (6) is a subset of (4), so only condition (6) needs to be satisfied., i.e., requirement:

$$
\sigma_{3}^{2} \leq d_{3}((1-\omega)+(1-\mu))
$$

The parameter $\sigma_{3}$ is the risk fluctuation of the reserve part, which mainly depends on the size of the claim. The more stable the claim is, the smaller the fluctuation is, and the easier the system is to enter a stable state.

Although from the expression, the higher the reserve payment rate $d_{3}$, the easier condition (6) is to meet, but combined with condition (1), the higher the reserve payment rate, the easier it is to violate condition (1), so the reserve payment rate needs to be in a suitable range. The same is true for parameters $\omega$ and $\mu$.

In condition (6), we can see that $1-\omega$ and $1-\mu$ are actually in the state of health and risk, and the remaining part after the funds are transferred to the reserve state. Condition (6) actually requires that the remaining funds under these two states should be able to resist the risk fluctuation of claim.

In a word, the insurance organization can make the capital flow system tend to a stable state by adjusting the investment strategy and even the provision so that the funds in the three states fluctuate in a limited range near $\left(S^{*}, a I^{*}, b R^{*}\right)$. The $\left(S^{*}, a I^{*}, b R^{*}\right)$ is positive; that is to say, in the dynamic process of inflow and outflow of funds in each state, the system can maintain greater than zero, and the system is stable and has solvency; otherwise, the system may tend to fail, leading to insufficient solvency. Moreover, we can see that if the risk $\sigma_{2}$ and $\sigma_{3}$ of risk status and reserve status are larger, the values of parameters $a$ and $b$ will increase accordingly; that is, more funds are required to resist the risk.

\section{Numerical Simulation}

Further numerical simulation is carried out to verify the conditions of solvency of insurance companies. When the external environment changes, the insurance company can take the strategy to maintain solvency.

5.1. The Stability Condition Is Satisfied. Assuming that the values of each parameter are $\lambda=0.1, \beta=0.4, d_{3}=0.9$, 


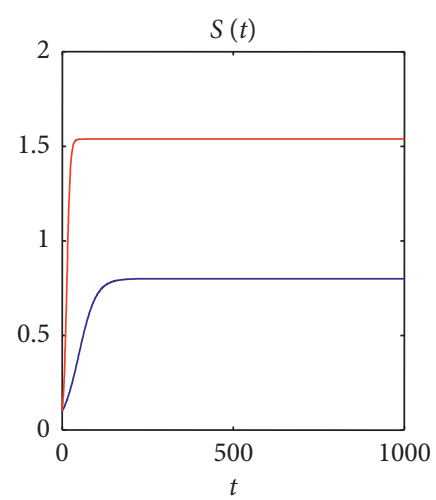

(a)

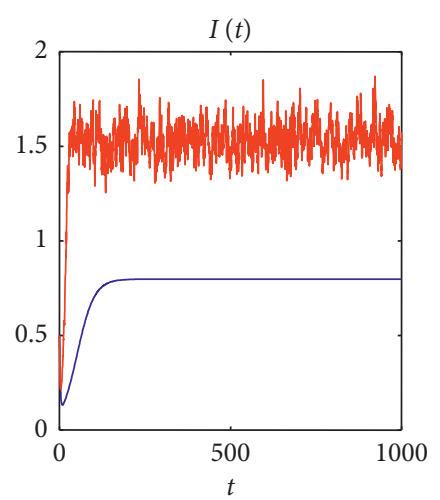

(b)

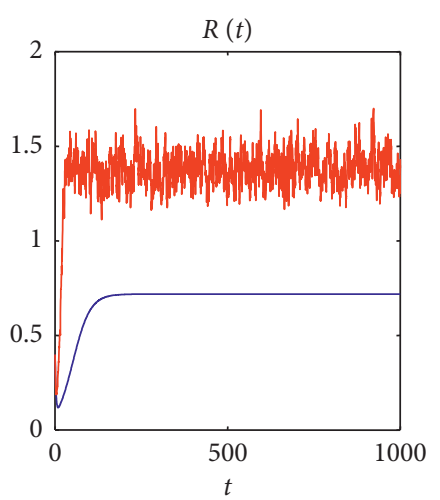

(c)

FIgURE 2: Trend of capital flow under stable conditions.

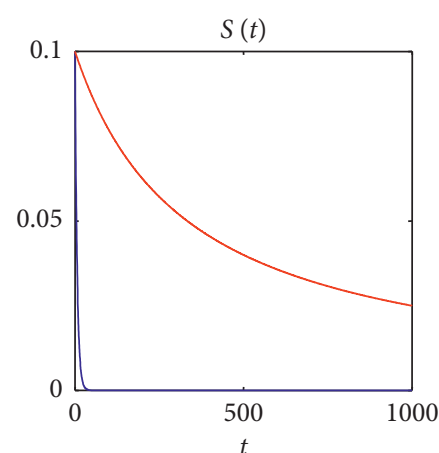

(a)

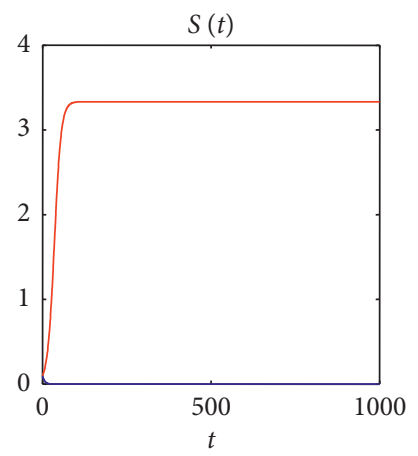

(d)

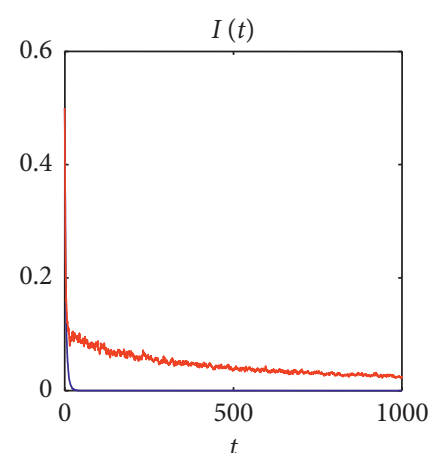

(b)

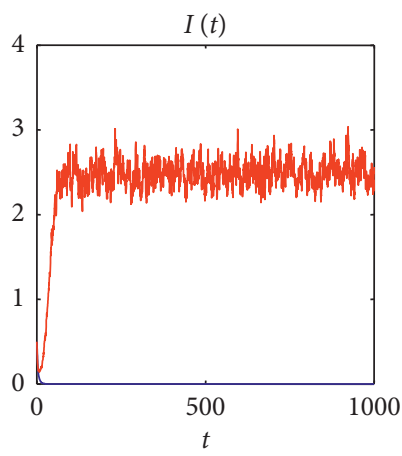

(e)

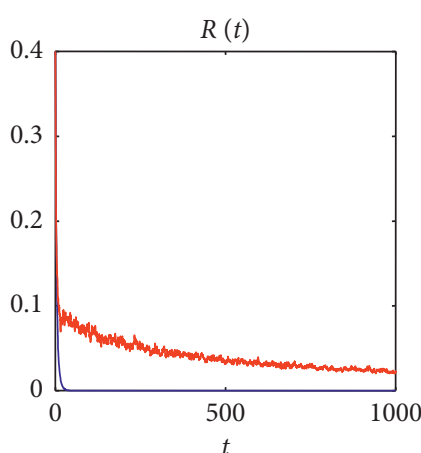

(c)

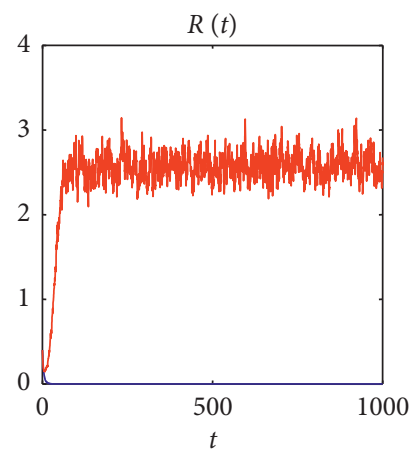

(f)

Figure 3: Trend of capital flow under negative growth rate.

$\omega=0.4, \quad d_{1}=0.3, \quad r=0.05, \quad \mu=0.5, \quad d_{2}=0.001, \quad$ and $\sigma_{1}=\sigma_{2}=\sigma_{3}=0.05$, respectively, and it obviously meets the solvency conditions of the insurance company. The dynamic trend of capital flow in each state is shown in Figure 2. It can be seen that they can fluctuate near the stable point greater than zero and maintain solvency.

5.2. The Growth Rate Decreases. If the premium growth rate of insurance company $\lambda<0$, that is, the premium has a negative growth, we can adjust the investment proportion parameter $\beta$ to meet the stability conditions and maintain solvency; for example, when the premium growth rate is $\lambda=$ -0.1 and other parameters remain unchanged, the insurance company can still meet the conditions and meet the solvency requirements by reducing the control variable investment ratio $\beta=0.4$ to $\beta=0.3$.

As shown in Figure 3, the trend of capital flow under $\beta=$ 0.4 in the first line shows that the capital in each state tends to zero and the solvency is insufficient. The second is the trend of capital flow of $\beta=0.3$, and the capital of each state can still fluctuate around the point greater than zero and has solvency.

5.3. The Loss Ratio Increases. If the insurance company's loss ratio increases, it can still adjust the investment proportion parameter $\beta$ to meet the stability conditions and maintain solvency; for example, the rise of claim leads to the increase 


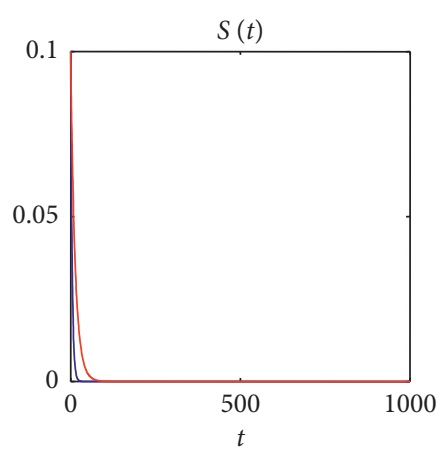

(a)

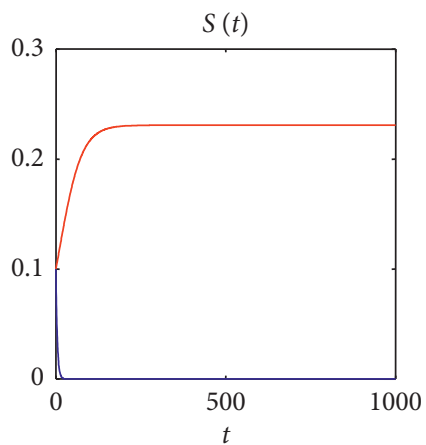

(d)

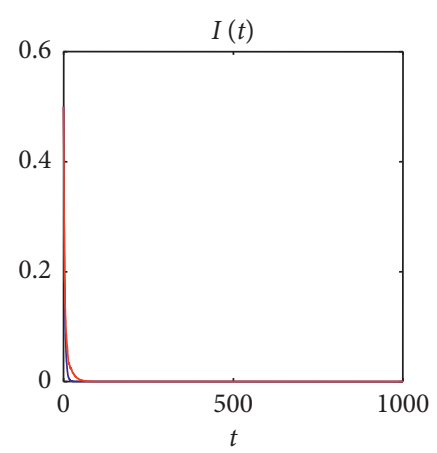

(b)

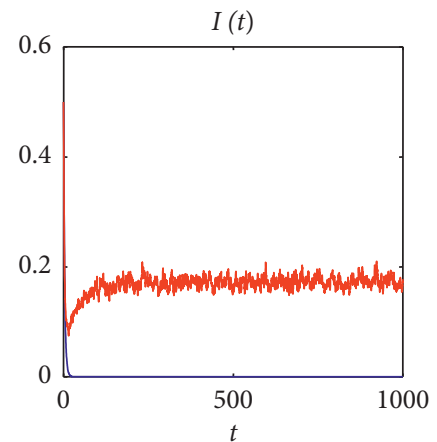

(e)

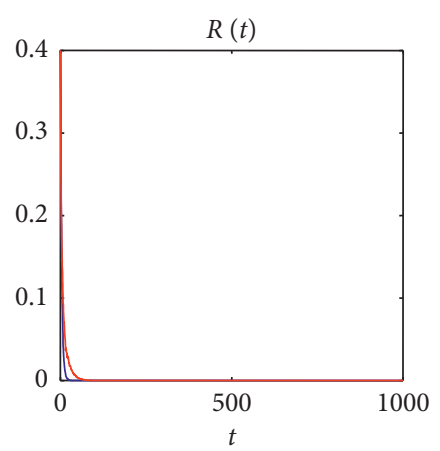

(c)

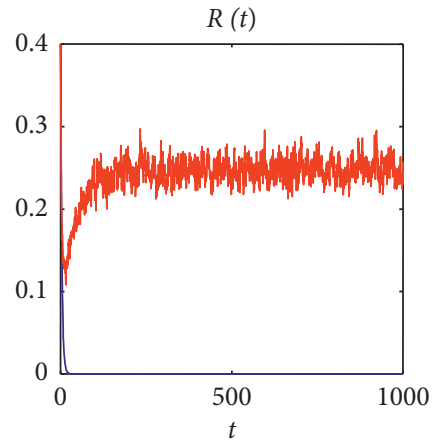

(f)

Figure 4: Trend of capital flow when loss ratio increases.

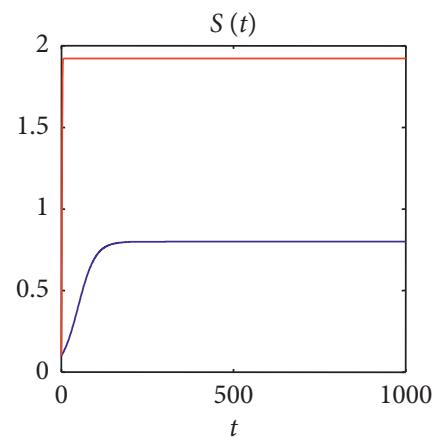

(a)

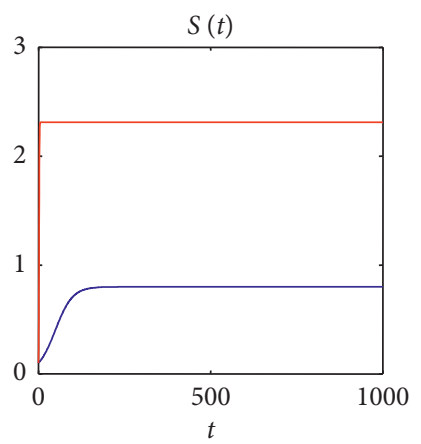

(d)

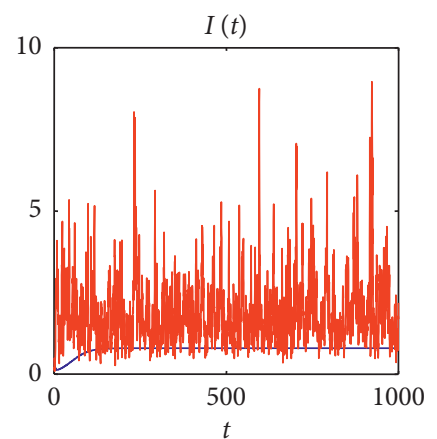

(b)

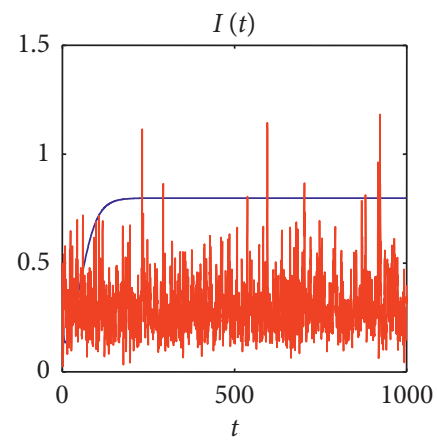

(e)

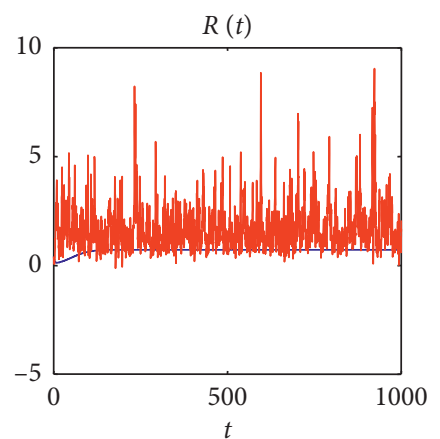

(c)

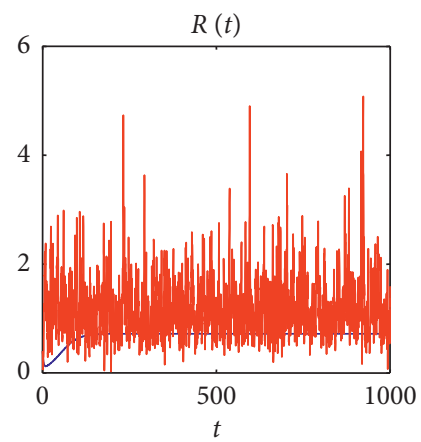

(f)

FIGURE 5: Trend of capital flow when volatility increases. 
in reserve ratio from $\omega=0.4$ to $\omega=0.7$. Under the condition of keeping other parameters unchanged, the insurance company can still meet the conditions and meet the solvency requirements by reducing the investment proportion of control variable $\beta=0.4$ to $\beta=0.3$.

As shown in Figure 4, when $\omega=0.7$, the first line is the trend of capital flow under $\beta=0.4$. Obviously, the capital in each state tends to zero and the solvency is insufficient. The second behavior is the trend of capital flow under $\beta=0.3$. The capital of each state can still fluctuate around the point greater than 0 and has solvency.

5.4. Volatility Increases. If the investment volatility or claim volatility increases, the insurance company can adjust the parameters $\beta$ and $\mu$ at the same time to meet the stability conditions and maintain solvency; for example, when the volatility increases from $\sigma=0.05$ to $\sigma=0.45$ and other parameters remain unchanged, the insurance company can still meet the solvency requirements by reducing the control variable $\beta=0.4$ to $\beta=0.1$ and increasing $\mu=0.5$ to $\mu=0.9$.

As shown in Figure 5, when $\sigma=0.45$, the first line in the figure is the trend of capital flow when $\beta=0.4$ and $\mu=0.5$, in which the capital in reserve state may have been reduced to below zero, and the solvency is insufficient. The second behavior is $\beta=0.1$ and $\mu=0.9$. We can see that the capital in the reserve state still keep above zero, which reduces the possibility of insufficient solvency.

\section{Conclusion}

From the perspective of capital flow, this paper regards the capital flow of insurance company as a dynamic system, and the solvency depends on the stability of capital flow in different states. The stochastic differential equations are used to characterize the change characteristics of the system. By proving, the existence of the equilibrium point greater than zero of the stochastic system and the condition of stable fluctuation near the equilibrium point are obtained, that is, the condition that the insurance company has solvency, which requires the insurance company's premium growth rate, investment ratio, loss ratio, expense ratio, return on investment, volatility of investment income, and claim to meet three conditions: (1) $\lambda+1-\left(\beta+d_{3} \omega+d_{1}\right)>0$; (2) $\sigma_{2}^{2} \leq-2\left(r-d_{2}\right)-\beta+d_{3} \mu$; (3) $\sigma_{3}^{2} \leq d_{3}((1-\omega)+(1-\mu))$.

When the external environment of the insurance company changes, such as negative premium growth, loss ratio growth, or increased volatility, the insurance company can adjust the control variable parameters, such as investment proportion $\beta$ and investment capital transfer proportion $\mu$, so that they can meet the stable conditions, maintain solvency, and have the strategies to deal with insufficient solvency.

\section{Appendix}

Proof of Proposition 1

According to

$$
\begin{aligned}
& S^{*}=\frac{K}{\lambda}\left[1+\lambda-\left(\beta+d_{3} \omega+d_{1}\right)\right], \\
& I^{*}=\frac{\beta}{-r+d_{3} \mu+d_{2}} S^{*}, \\
& R^{*}=\omega S^{*}+\mu I^{*},
\end{aligned}
$$

then define

$$
\begin{aligned}
V(S, I, R)= & \frac{K}{\lambda}\left(\frac{\beta}{2}+\frac{d_{3} \omega}{2}+1\right)\left(S-S^{*}-S^{*} \ln \frac{S}{S^{*}}\right) \\
& +\frac{1}{2}\left(I-I^{*}\right)^{2}+\frac{1}{2}\left(R-R^{*}\right)^{2} \\
:= & V_{1}+V_{2}+V_{3} .
\end{aligned}
$$

Obviously, $V$ is the positive definite, as can be seen from Ito's formula:

$$
\begin{aligned}
\mathrm{d} V(S, I, R):= & \left(L V_{1}+L V_{2}+L V_{3}\right) \mathrm{d} t+\sigma_{1}\left(S-S^{*}\right) \mathrm{d} B_{1}(t) \\
& +\sigma_{2}\left(I-I^{*}\right) \mathrm{d} B_{2}(t)+\sigma_{3}\left(R-R^{*}\right) \mathrm{d} B_{3}(t)
\end{aligned}
$$

where

$$
\begin{aligned}
L V_{1}= & \frac{K}{\lambda}\left(\left(\frac{\beta}{2}+\frac{d_{3} \omega}{2}+1\right)\left(1-\frac{S^{*}}{S}\right)\left(\lambda S\left(1-\frac{S}{K}\right)\right)+S-\beta S-\omega S-d_{1} S\right)+\frac{K}{2 \lambda}\left(\frac{\beta}{2}+\frac{d_{3} \omega}{2}+1\right) \sigma_{1}^{2} S^{*} \\
= & \frac{K}{\lambda}\left(\frac{\beta}{2}+\frac{d_{3} \omega}{2}+1\right)\left(S-S^{*}\right)\left(-\frac{\lambda}{K} S+\lambda+1-\beta-\omega-d_{1}\right) \\
& +\frac{K}{2 \lambda}\left(\frac{\beta}{2}+\frac{d_{3} \omega}{2}+1\right) \sigma_{1}^{2} S^{*} \\
= & -\left(\frac{\beta}{2}+\frac{d_{3} \omega}{2}+1\right)\left(S-S^{*}\right)^{2}+\frac{K}{2 \lambda}\left(\frac{\beta}{2}+\frac{d_{3} \omega}{2}+1\right) \sigma_{1}^{2} S^{*},
\end{aligned}
$$




$$
\begin{aligned}
& L V_{2}=\left(I-I^{*}\right)\left(\beta S+r I-d_{3} \mu I-d_{2} I-\beta S^{*}-r I^{*}+\mu I^{*}+d_{2} I^{*}\right)+\frac{1}{2} \sigma_{2}^{2} I^{2} \\
& =\beta\left(I-I^{*}\right)\left(S-S^{*}\right)-\left(r+d_{3} \mu+d_{2}\right)\left(I-I^{*}\right)^{2}+\frac{1}{2} \sigma_{2}^{2} I^{2} \\
& \leq \frac{\beta}{2}\left(I-I^{*}\right)^{2}+\frac{\beta}{2}\left(S-S^{*}\right)^{2}-\left(r+d_{3} \mu+d_{2}\right)\left(I-I^{*}\right)^{2}+\frac{1}{2} \sigma_{2}^{2} I^{2}, \\
& L V_{3}=\left(R-R^{*}\right)\left(d_{3} \omega S+\mu I-d_{3} R-d_{3} \omega S^{*}-\mu I^{*}+d_{3} R^{*}\right)+\frac{1}{2} \sigma_{3}^{2} R^{2} \\
& =d_{3} \omega\left(R-R^{*}\right)\left(S-S^{*}\right)+d_{3} \mu\left(R-R^{*}\right)\left(I-I^{*}\right)-d_{3}\left(R-R^{*}\right)^{2}+\frac{1}{2} \sigma_{3}^{2} R^{2} \\
& \leq\left(\frac{d_{3} \omega}{2}+\frac{d_{3} \mu}{2}\right)\left(R-R^{*}\right)^{2}+\frac{d_{3} \omega}{2}\left(S-S^{*}\right)^{2}+\frac{d_{3} \mu}{2}\left(I-I^{*}\right)^{2}-d_{3}\left(R-R^{*}\right)^{2}+\frac{1}{2} \sigma_{3}^{2} R^{2}, \\
& L V_{1}+L V_{2}+L V_{3} \leq-\left(S-S^{*}\right)^{2}-\left(r+\frac{d_{3} \mu}{2}+d_{2}-\frac{\beta}{2}\right)\left(I-I^{*}\right)^{2}-\left(d_{3}-\frac{d_{3} \omega}{2}-\frac{d_{3} \mu}{2}\right)\left(R-R^{*}\right)^{2} \\
& +\frac{K}{\lambda}\left(\frac{\beta}{2}+\frac{\omega}{2}+1\right) \sigma_{1}^{2} S^{*}+\sigma_{2}^{2} I^{2}+\sigma_{3}^{2} R^{2} \\
& \leq-\left(S-S^{*}\right)^{2}-\left(r+\frac{d_{3} \mu}{2}+d_{2}-\frac{\beta}{2}-\frac{1}{2} \sigma_{2}^{2}\right)\left(I-a I^{*}\right)^{2}-\left(d_{3}-\frac{d_{3} \omega}{2}-\frac{d_{3} \mu}{2}-\frac{1}{2} \sigma_{3}^{2}\right)\left(R-b R^{*}\right)^{2} \\
& +\frac{K}{2 \lambda}\left(\frac{\beta}{2}+\frac{d_{3} \omega}{2}+1\right) \sigma_{1}^{2} S^{*}+a \sigma_{2}^{2} I^{* 2}+b \sigma_{3}^{2} R^{* 2} \\
& a=\frac{r+\left(d_{3} \mu / 2\right)+d_{2}-(\beta / 2)}{r+\left(d_{3} \mu / 2\right)+d_{2}-(\beta / 2)-(1 / 2) \sigma_{2}^{2}} \\
& b=\frac{d_{3}-\left(d_{3} \mu / 2\right)-\left(d_{3} \mu / 2\right)}{d_{3}-\left(d_{3} \mu / 2\right)-\left(d_{3} \mu / 2\right)-(1 / 2) \sigma_{3}^{2}} \\
& \mathrm{~d} V(S, I, R) \leq\left[-\left(S-S^{*}\right)^{2}-\left(r+\frac{d_{3} \mu}{2}+d_{2}-\frac{\beta}{2}-\frac{1}{2} \sigma_{2}^{2}\right)\left(I-a I^{*}\right)^{2}-\left(d_{3}-\frac{d_{3} \omega}{2}-\frac{d_{3} \mu}{2}-\frac{1}{2} \sigma_{3}^{2}\right)\left(R-b R^{*}\right)^{2}\right. \\
& +\frac{K}{2 \lambda}\left(\frac{\beta}{2}+\frac{d_{3} \omega}{2}+1\right) \sigma_{1}^{2} S^{*}+a \sigma_{2}^{2} I^{* 2}+b \sigma_{3}^{2} R^{* 2} \mathrm{~d} t \\
& +\sigma_{1}\left(S-S^{*}\right) \mathrm{d} B_{1}(t)+\sigma_{2}\left(I-I^{*}\right) I \mathrm{~d} B_{2}(t)+\sigma_{3}\left(R-R^{*}\right) R \mathrm{~d} B_{3}(t) .
\end{aligned}
$$

Therefore,

$$
\begin{aligned}
& \int_{0}^{t}\left[-\left(S-S^{*}\right)^{2}-\left(r+\frac{d_{3} \mu}{2}+d_{2}-\frac{\beta}{2}-\frac{1}{2} \sigma_{2}^{2}\right)\left(I-a I^{*}\right)^{2}-\left(d_{3}-\frac{d_{3} \omega}{2}-\frac{d_{3} \mu}{2}-\frac{1}{2} \sigma_{3}^{2}\right)\left(R-b R^{*}\right)^{2}\right] \mathrm{d} t \\
& \leq V(0)+\left[\frac{K}{2 \lambda}\left(\frac{\beta}{2}+\frac{d_{3} \omega}{2}+1\right) \sigma_{1}^{2} S^{*}+a \sigma_{2}^{2} I^{* 2}+b \sigma_{3}^{2} R^{* 2}\right] t \\
& \quad+\int_{0}^{t} \sigma_{1}\left(S-S^{*}\right) \mathrm{d} B_{1}(t)+\int_{0}^{t} \sigma_{2}\left(I-I^{*}\right) I \mathrm{~d} B_{2}(t)+\int_{0}^{t} \sigma_{3}\left(R-R^{*}\right) R \mathrm{~d} B_{3}(t) .
\end{aligned}
$$

Let

$$
\begin{aligned}
M_{t} & =\int_{0}^{t} \sigma_{1}\left(S-S^{*}\right) \mathrm{d} B_{1}(t)+\int_{0}^{t} \sigma_{2}\left(I-I^{*}\right) I \mathrm{~d} B_{2}(t) \\
& +\int_{0}^{t} \sigma_{3}\left(R-R^{*}\right) R \mathrm{~d} B_{3}(t) .
\end{aligned}
$$

Then, $M_{t}$ is a real-valued continuous local martingale, $M_{0}=0$, with

$$
\frac{\langle M, M\rangle_{t}}{t}<\infty
$$

So, $\lim _{t \longrightarrow \infty}\left(M_{t} / t\right)=0 a . s$, and therefore, 


$$
\limsup _{t \longrightarrow \infty} \frac{1}{t} \int_{0}^{t}\left(S-S^{*}\right)^{2}+\left(I-a I^{*}\right)^{2}+\left(R-b R^{*}\right)^{2} \mathrm{~d} s \leq \frac{K_{\sigma}}{M}, \quad \text { a.s }
$$

where

$$
\begin{aligned}
S^{*} & =\frac{K}{\lambda}\left(1+\lambda-\left(\beta+d_{3} \omega+d_{1}\right)\right), \\
I^{*} & =\frac{\beta}{-r+d_{3} \mu+d_{2}} S^{*}, \\
R^{*} & =\omega S^{*}+\mu I^{*}, \\
M & =\min \left\{r+\frac{d_{3} \mu}{2}+d_{2}-\frac{\beta}{2}-\frac{1}{2} \sigma_{2}^{2}, d_{3}-\frac{d_{3} \omega}{2}-\frac{d_{3} \mu}{2}-\frac{1}{2} \sigma_{3}^{2}\right\}, \\
K_{\sigma} & =\frac{K}{2 \lambda}\left(\frac{d_{3} \omega}{2}+\frac{d_{3} \mu}{2}+1\right) S^{*} \sigma_{1}^{2}+a I^{* 2} \sigma_{2}^{2}+b R^{* 2} \sigma_{3}^{2} .
\end{aligned}
$$

\section{Data Availability}

According to the survey results of the annual report data of Chinese insurance companies, the data are reasonably estimated.

\section{Conflicts of Interest}

The authors declare that there are no conflicts of interest regarding the publication of this paper.

\section{Authors' Contributions}

Kai Wang and Ling Zhu contributed equally to this work.

\section{Acknowledgments}

This work was supported by the General Project of Anhui Natural Science Foundation (Grant no. 1908085MG237) and the Key Project of Natural Science Research in Anhui Colleges and Universities (Grant no. KJ2019A0217).

\section{References}

[1] E. Martin, H. Schmeiser, T. Joan, and Schmit, "The solvency II process: overview and critical analysis," Risk Management and Insurance Review, vol. 10, no. 1, pp. 69-85, 2007.

[2] M. Drenovak, V. Ranković, B. Urošević, and R. Jelic, "Bond portfolio management under solvency II regulation," The European Journal of Finance, vol. 26, pp. 1-23, 2020.

[3] A. J. Pelkiewicz, S. W. Ahmed, P. Fulcher et al., "A review of the risk margin - solvency II and beyond," British Actuarial Journal, vol. 25, no. e1, pp. 1-72, 2020.

[4] J. Cooke, A. Scott, D. Smith et al., "Recalculation of the solvency II transitional measures on technical provisions," British Actuarial Journal, vol. 24, no. e12, pp. 1-87, 2019.

[5] R. A. Rae, A. Barrett, D. Brooks, M. A. Chotai, A. J. Pelkiewicz, and C. Wang, "A review of solvency II: has it met its objectives?" British Actuarial Journal, vol. 23, no. e4, pp. 1-72, 2018.

[6] S. Pablo Duran, O. G. Luís, M. Onofre, M. Anna, and L. Gil, "Property risk under solvency II: effects of different unsmoothing techniques," Technological and Economic Development of Economy, vol. 25, pp. 1-19, 2019.

[7] M. Scherer and G. Stahl, "The standard formula of solvency II: a critical discussion," European Actuarial Journal, vol. 11, pp. 13-31, 2020.

[8] K. Gunther and A. Richter, "Insurance regulation and life catastrophe risk: treatment of life catastrophe risk under the SCR standard formula of solvency II and the necessity of partial internal models," Geneva Papers on Risk and Insurance - Issues and Practice, vol. 40, no. 2, pp. 256-278, 2015.

[9] K. Tan and A. Bruhn, "Comparing Solvency II and Life and General Insurance Capital approaches to capital determination of a life portfolio in the presence of stress scenarios," Annals of Actuarial Science, vol. 13, no. 1, pp. 1-31, 2019.

[10] M. Di Francesco, "Portfolio optimization under solvency II: a multi-objective approach incorporating market views and real-world constraints," Decisions in Economics and Finance, vol. 1, pp. 123-148, 2021.

[11] L. Fernandez-Arjona, "A neural network model for solvency calculations in life insurance," 2020, http://arxiv.org/abs/ 12005.02318 .

[12] A. Braun, H. Schmeiser, and F. Schreiber, "Portfolio optimization under solvency II: implicit constraints imposed by the market risk standard formula," Journal of Risk and Insurance, vol. 84, no. 1, pp. 177-207, 2017.

[13] M. Escobar, K. Paul, M. Wahl, and R. Zagst, "Portfolio optimization under solvency II," Annals of Operations Research, vol. 20, pp. 69-81, 2018.

[14] A. V. Asimit, A. M. Badescu, Tak Kuen Siu, and T. K. Y. Zinchenko, "Capital requirements and optimal investment with solvency probability constraints," IMA Journal of Management Mathematics, vol. 26, no. 4, pp. 345-375, 2015.

[15] E. D'.O. Nicolino, G. Marcarelli, and G. Melisi, "Loss portfolio transfer treaties within solvency II capital system: a reinsurer's point of view," Insurance Markets and Companies, vol. 1, pp. 1-10, 2020.

[16] D. Pfeifer, "Modellvalidierung mit Hilfe von Quantil-QuantilPlots unter Solvency II," Zeitschrift für die gesamte Versicherungswissenschaft, vol. 108, no. 3-4, pp. 307-325, 2019.

[17] P. G Durán Santomil and L. Otero González, "Enterprise risk management and solvency II: the system of governance and the own risk and solvency assessment," The Journal of Risk Finance, vol. 21, no. 4, pp. 317-332, 2020.

[18] L. Jansen van Vuuren, M. Reyers, and C. H. van Schalkwyk, "Assessing the impact of solvency assessment and management on risk management in South African insurance companies," Southern African Business Review, vol. 21, no. 1, pp. 129-149, 2017.

[19] K. Wang, L. Fang, and J. Cheng, "Management of commissions to meet the regulatory requirements: the case of property-casualty insurance in China," The Geneva Papers on Risk and Insurance - Issues and Practice, vol. 45, no. 3, pp. 508-534, 2020.

[20] X. Lu and D. Hong, "Using Monte Carlo simulation to predict captive insurance solvency," in Proceedings of the 2020 the 4th International Conference on Compute and Data Analysis, pp. 84-88, Shenzhen, China, March 2020.

[21] V. Mucha-Michal and S. Páleś-Katarína, "Calculation of the capital requirement using the Monte Carlo simulation for 
non-life insurance," Ekonomický Časopis, vol. 64, no. 9, pp. s878-893, 2016.

[22] L. Bermúdez, A. Ferri, and M. Guillén, "A correlation sensitivity analysis of non-life underwriting risk in solvency capital requirement estimation," ASTIN Bulletin, vol. 43, no. 1, pp. 21-37, 2013.

[23] H. Mejdoub and M. Ben Arab, "Impact of dependence modeling of non-life insurance risks on capital requirement: D-vine copula approach," Research in International Business and Finance, vol. 45, no. 10, pp. 208-218, 2018.

[24] K. Hanewald, T. Post, and H. Gründl, "Stochastic mortality, macroeconomic risks and life insurer solvency," The Geneva Papers on Risk and Insurance - Issues and Practice, vol. 36, no. 3, pp. 458-475, 2011.

[25] J. Valecký, "Calculation of solvency capital requirements for non-life underwriting risk using generalized linear models," Prague Economic Papers, vol. 26, no. 4, pp. 450-466, 2017.

[26] B. Vaucher, "Optimal equity protection of solvency II regulated portfolios," Journal of Risk, vol. 20, no. 3, pp. 69-81, 2018.

[27] Ł. Delong, "An optimal investment strategy for a stream of liabilities generated by a step process in a financial market driven by a Lévy process," Insurance: Mathematics and Economics, vol. 47, no. 3, pp. 278-293, 2010.

[28] Ł. Delong and R. Gerrard, "Mean-variance portfolio selection for a non-life insurance company," Mathematical Methods of Operations Research, vol. 66, no. 2, pp. 339-367, 2007.

[29] S. Xiong, Stochastic Diferential Equations: Some Risk and Insurance Applications, Temple University, Philadelphia, PA, USA, 2011.

[30] Y.-F. Shi, Z. De-li, and H. Li-min, "“Arbitrage free life insurance pricing model based on individual equity principle," in Proceedings of the 2008 International Conference on Management Science and Engineering 15th Annual Conference Proceedings, pp. 205-210, Chongqing, China, November 2008.

[31] E. Paul, "Pricing general insurance with constraints," Insurance: Mathematics and Economics, vol. 40, no. 2, pp. 335-355, 2007.

[32] A. Floryszczak, J. Levy Vehel, and M. Majri, "A conditional equity risk model for regulatory assessment," Astin Bulletin, vol. 49, no. 1, pp. 1-26, 2018. 